\title{
La Atención Primaria de Salud en el Ecuador
}

\author{
Dr. Plutarco Naranjo \\ Universidad Andina "Simón Bolívar" \\ Academia Ecuatoriana de Medicina, Quito.
}

\section{Antecedentes}

$\mathrm{T}$ Mundial tras algunas gestiones iniciadas por las Potencias Aliadas, en 1945 se creó la Organización de las Naciones Unidas (ONU) con el propósito fundamental de mantener la paz y la seguridad entre las naciones del mundo. Con este objetivo se crearon varias entidades o agencias dependientes de la ONU, entre ellas la Organización Mundial de la Salud (OMS), la cual superando la época del simple sanitarismo y de la curación de enfermos encaró el más amplio objetivo el de promoción de la salud.

Desde entonces y con la activa participación de todos los gobiernos miembros de la ONU, la OMS ha realizado campañas y programas que han contribuido a mejorar la salud del mundo. Sin embargo los resultados no fueron lo suficientemente satisfactorios. Los indicadores de salud habían mejorado pero mucho menos que lo esperado. La mortalidad infantil seguía alta, la desnutrición de niños y madres seguía igual o peor, los recursos de los gobiernos seguían dedicados principalmente a curar enfermos, los hospitales consumían la mayor parte de los presupuestos de "salud", la inequidad en salud (y también en educación) era evidente sobre todo en los países del Tercer Mundo.

Frente a estas circunstancias la OMS convocó a los gobiernos miembros a una Conferencia Mundial que se efectuó en 1978 en Alma. Ata (Unión Soviética), la misma que entre otras declaraciones hizo las siguientes: "La Conferencia reafirma con decisión, que la salud, que es un estado de completo bienestar físico, mental. $y$ social, $y$ no 
sólo la ausencia de enfermedad; es un derecho humano fundamental y que la consecución del nivel de salud más alto posible es un objetivo social prioritario en todo el mundo, cuya realización requiere acción de muchos otros sectores sociales y económicos, además del sector sanitario.

La existente desigualdad en el estado de salud de las personas, particularmente entre los países desarrollados y los países en vías de desarrollo, así como entre los diversos países, es inaceptable política, social y económicamente y, por tanto, implica de manera común a todos los países".

Y por último aprobó una altruista meta que se denominó "Salud para todos en el año 2000" y estableció la estrategia para alcanzar esa meta la "Atención Primaria de Salud" (APS).

A pesar de que el año 2000 quedó ya atrás y que la denominación de Atención Primaria de Salud ha entrado hasta en el lenguaje común, todavía no es muy conocida ni entendida entre muchos médicos., Facultades de Medicina, menos aún entre ciertos organismos gubernamentales. Se sigue con el anacrónico y limitado objetivo de "curar enfermos" soslayando el abordar las verdaderas causas de la enfermedad. Para citar un ejemplo, la diarrea infantil sigue siendo una de las principales causas de morbilidad y mortalidad infantil. ¿Qué se hace?, curar a los niños enfermos. Desde los tiempos de Hipócrates se proclama el apotegma de que "es mejor prevenir que curar". ¿Por qué la alta prevalencia de la diarrea infantil? Por la sencilla razón de que el $50 \%$ de la población no dispone de servicios de eliminación de excretas ni de agua segura. Lo lógico es atacar a las causas primarias: proveer de saneamiento básico y agua segura.

La Atención Primaria de Salud.

Esta estrategia no significa atención elemental o de primeros auxilios. Todo lo contrario significa orientar las acciones de salud, con criterio epidemiológico, hacia lo más esencial y prioritario en cada país. No siendo posible atender eficientemente todos los problemas en forma simultánea, sobre todo no disponiendo de los enormes recursos económicos que se requieren para atender los variados problemas de salud, es indispensable priorizar los programas y acciones.

Aspecto muy importante es el énfasis en la protección y promoción de la salud a través de la inmunización de los niños contra las enfermedades transmisibles, el saneamiento básico, la dotación de agua segura y otros programas, superando la época meramente curativa o la simple extensión o incremento de las "coberturas". 
Los componentes esenciales de la APS son:

\section{1.- Saneamiento básico y agua se- gura.}

Como se ha mencionado ya, la mejor manera de prevenir la diarrea sobre todo de los niños y otras enfermedades es saneando el medio ambiente, es decir, mediante la eliminación sanitaria de fecales y otros desechos y dotando a las comunidades de sistemas de agua potable o agua segura.

Durante toda una década se han suspendido las obras sanitarias. Un gobierno que actúe con responsabilidad, frente al mandato constitucional de garantizar la salud del pueblo ecuatoriano debe, como política nacional, emprender urgentemente, en el plan de dotar de servicios de alcantarillado o de letrinas y de agua segura, a los sectores del país, que carecen de estos servicios. Si aún las grandes ciudades como Quito y Guayaquil no disponen suficientemente de estos servicios en las zonas urbanas marginales, es fácil comprender como es la situación en las zonas rurales y más en las de población aborígenes, dispersas.

El Municipio Metropolitano de Quito se ha concienciado de este grave problema y en el presente cuatrienio ha extendido la red de alcantarillado en una extensión de cerca de 1.000 kilómetros, y de más de 1.000 kilómetros de la red de agua potable, en los barrios periféricos. Ojalá este ejemplo sea puesto en práctica en otras ciudades, en especial, en la más populosa, Guayaquil.

Independientemente de los municipios, el gobierno nacional debe planificar y realizar las obras necesarias en el resto del pals. En buena parte de los páramos poblados y zonas rurales no se justifica construir costosas redes sanitarias. Allá es necesario construir letrinas.

En el cuatrienio de 1988 a 1992 se desarrolló un programa de letrinización con la colaboración de las comunidades y usuarios. El Ministerio de Salud Pública, a través del IEOS proporcionó la dirección técnica y los materiales, y los usuarios la mano de obra. Al Ministerio le costó alrededor de 50 dólares por letrina. En ese tiempo se consideró que el déficit de letrinas, en el país, era más de un millón de unidades.

En el Ecuador con muy buen criterio se creó el Instituto de Obras Sanitarias (IEOS) que ha desempeñado un papel importantísimo en el cuadrienio 1988-1992. Con apropiada planificación y como integrante del Ministerio de Salud, realizó obras de saneamiento y agua, más de lo que se había hecho en los 170 años anteriores de la República. Desgraciadamente luego al IEOS se le ha arrinconado en el Ministerio de la Vivienda.

\section{2.- Alimentación y nutrición.}

La desnutrición, en especial en los niños y madres embarazadas, constituye uno de los más graves problemas 
biológicos, médicos y socioeconómicos del país. El niño desnutrido no desarrolla en forma apropiada sus defensas inmunológicas y es fácil presa de las infecciones. No crece ni se desarrolla ni en lo físico ni en lo intelectual de acuerdo a sus potencialidades biológicas, por consiguiente el aspecto fundamental para asegurar la salud es la alimentación y nutrición apropiadas.

La encuesta nacional realizada en 1987 reveló que la desnutrición afectaba al $50 \%$ de los niños menores de 5 años. En investigaciones realizadas entre 1990 y 1991 se encontró que, según los sitios, entre el 30 y $40 \%$ de madres que daban a luz en las maternidades u hospitales públicos, adolecían de desnutrición y anemia. Los niños de estas madres nacen también desnutridos y anémicos y entre el 10 y $15 \%$ son de bajo peso, es decir de menos de 2.500 gm. al nacer. Algunos nacen con signos de desnutrición crónica, pues la madre ya estaba desnutrida antes del embarazo, empeoró durante éste y el resultado final ya señalado.

Como es bien sabido, la pobreza y la indigencia son los principales determinantes de la desnutrición. Hay falta de fuentes de trabajo, hay creciente desocupación y desempleo que llevan a la pobreza. La dolarización del país aunque ha contribuido a la estabilidad cambiaria, en cambio, ha determinado un aumento de la pobreza y lá desnutrición.
Cierto que los cientos de miles de ecuatorianos que han emigrado a EE.UU., España y otros países y que remiten más de 1.500 millones de dólares al año, han aliviado la situación económica y alimentaria de sus respectivas familias, pero jel resto de la población? Es urgente que por parte del gobierno ponga en marcha un Plan $\mathrm{Na}$ cional de Nutrición, con recursos, procedimientos y metas apropiadas.

\section{3.- Educación para la salud.}

La educación es un derecho individual y colectivo, pero también es una obligación. Para prevenir y fomentar la salud es indispensable tener un mínimo de conocimientos sobre ella, es decir la educación para la salud debe ejercitarse a todo nivel y a toda edad, parte muy útil de ella es la educación alimentaria, pues en el Ecuador como se anotó ya la desnutrición afecta a más del $50 \%$ de los niños.

4.- Salud materno-infantil y planificación familiar.

Los dos grupos de mayor riesgo están constituidos por los niños debido a su fragilidad y las madres durante el embarazo y la lactancia. La atención de salud, por lo mismo, debe priorizar la atención a estos dos grupos.

Parte importante de los programas materno-infantil y de educación para la salud es la planificación familiar. En la actualidad gracias a los conocimientos del proceso de la reproducción es posible planificar el tamaño de la familia. Sin entrar en aspectos económicos y las 
múltiples responsabilidades de la pareja frente a los hijos y sólo en relación a los riesgos biológicos para el futuro ser y sobre todo para la madre se ha formulado la sencilla regla sobre el embarazo: ni demasiado pronto (adolescente) ni demasiado tarde, ni muy seguido.

En el Ecuador aunque en las zonas urbanas ha disminuido el número de embarazos, por madre, en las zonas campesinas sigue siendo alto, y el control del embarazo es casi inexistente.

5.- Inmunización contra las principales enfermedades inmuno-prevenibles.

Disponiendo, como es posible, en la actualidad de recursos contra varias enfermedades, siendo relativamente sencillo el procedimiento de la inmunización es injustificable que aún queden muchos niños sin recibir el beneficio de las vacunas y que todavía se registren altos índices de mortalidad por enfermedades inmuno-prevenibles.

\section{6.-Prevención y control de ende- mias. \\ Donde hay pobreza e ignorancia} hay mayor número de enfermedades endémicas que hay que combatir tanto con medidas sanitarias cuanto con el tratamiento de los enfermos. En el Ecuador, desde hace años existe el paludismo o malaria entre las endemias de mayor trascendencia, en especial en la Costa y Amazonía Norte. En los años recientes se ha agregado el dengue.
7.- Tratamiento de enfermedades $y$ procedimientos comunes.

Hay que resaltar que los elementos anteriores de la APS, están enfocados a los aspectos preventivos, pero como a pesar de las medidas preventivas puede aparecer la enfermedad y mucho más donde las medidas profilácticas no han sido suficientes o eficientes, hay que afrontar entonces la parte curativa.

Es claro que mientras mayores sean las medidas preventivas menores son las necesidades curativas en especial para los niños, las madres y los pacientes de la tercera edad.

\section{8.- Provisión de medicamentos} esenciales.

Frente al inusitado crecimiento del arsenal farmacológico ha surgido el concepto de medicamentos esenciales.

La síntesis química ha permitido la proliferación de un enorme número de medicamentos. Después de la primera sulfonamida, ¿Cuántas fueron sintetizadas? Después del primer antibiótico, ¿cuántos han entrado en la terapia? Un hospital no puede tener los miles de medicamentos que hay en el mercado. Frente a esta exuberancia, la OMS desarrolló el concepto de medicamentos esenciales o indispensables que deben constituir la base de los llamados textos oficiales conocidos como "Cuadro Básico", "Recetario Básico o Institucional" u otros nombres.

El número de medicamentos esenciales está alrededor de 250, que cu- 
bren el tratamiento de aproximadamente el $90 \%$ de las enfermedades más comunes.

En el Ecuador, desde hace décadas existe un "Cuadro Básico de Medicamentos" en los hospitales del Seguro Social, también aunque un poco más tardías en el Ministerio de Salud y en los servicios médicos de las Fuerzas Armadas y de la Junta de Beneficencia de Guayaquil.

Estos instrumentos oficiales han sido actualizados cada cierto tiempo, de acuerdo a los nuevos medicamentos y a la obsolescencia de otros. Lo lamenta- ble es que en los hospitales y centros de salud del Ministerio no tienen existencias de todos los medicamentos aprobados y miles de pacientes se quedan con una inútil receta por no poder adquirir los medicamentos en farmacias públicas.

Sería aconsejable además que el "Cuadro Básico" llegue a manos de todos los médicos en ejercicio real de la medicina pues, por una parte orientan a un tratamiento más apropiado y en segundo lugar, son de calidad garantizada y casi siempre los más económicos. 